Int. J. Electrochem. Sci., 11 (2016) $9822-9838$

\title{
Synthesis of $\mathbf{2 H}$-benzotriazole based donor-acceptor polymers bearing carbazole derivative as pendant groups: Optical, electronical and photovoltaic properties
}

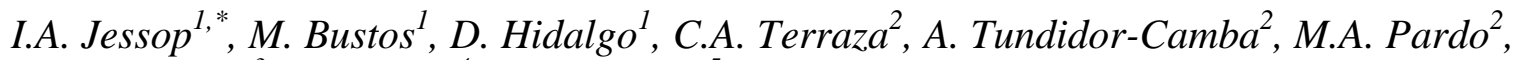 \\ D. Fuentealba ${ }^{3}$, M. Hssein ${ }^{4}$, J.C. Bernede \\ ${ }^{1}$ Universidad de Tarapacá, Facultad de Ciencias, Departamento de Química, Laboratorio de Materiales \\ Orgánicos y Poliméricos, Av. General Velásquez 1775, Arica, Chile. \\ ${ }^{2}$ Pontificia Universidad Católica de Chile, Facultad de Química, Departamento de Química Orgánica, \\ Laboratorio de Polímeros, Av. Vicuña Mackenna 4860, Macul, Santiago, Chile. \\ ${ }^{3}$ Pontificia Universidad Católica de Chile, Facultad de Química, Departamento de Química Física, \\ Laboratorio de Estructuras Biosupramoleculares, Av. Vicuña Mackenna 4860, Macul, Santiago, Chile. \\ ${ }^{4}$ Institut des Matériaux Jean Rouxel (IMN), CNRS, UMR 6502, 2 rue de la Houssinière, BP 32229, \\ 44322 Nantes cedex 3, France. \\ ${ }^{5}$ Université de Nantes, MOLTECH-Anjou, CNRS, UMR 6200, 2 rue de la Houssinière, BP 92208, \\ Nantes, F-44000 France. \\ *E-mail: iajessop@uta.cl
}

doi: $10.20964 / 2016.12 .43$

Received: 25 August 2016 / Accepted: 4 October 2016 / Published: 10 November 2016

Four 2H-benzotriazole based D-A polymers bearing carbazole derivative as pendant groups and fluorene or thiophene as donor units (P1-P4) were designed and synthesized. These polymers combine good thermal stability and excellent solubility in common organic solvents. Spectroscopic measurements carried out for P1, P2 and P3 indicate that polymer backbone induces effective the quenching of the 3,6-di(thiophen-2-yl)-9H-carbazole (CT) fluorescence, implying an intramolecular Förster Resonance Energy Transfer (FRET) process. Preliminary investigations on the photovoltaic multiheterojunction devices based on P1-P4 showed power conversion efficiencies (PCEs) of up to 1.7 $\%$ for $\mathbf{P 1}$ and $\mathbf{P 2}$ and close to $2.0 \%$ for $\mathbf{P 3}$. This means that the polymer/ $\pi$-conjugated pendant units structure is a promising alternative to improve the performance of organic solar cells.

Keywords: Donor-acceptor copolymers; pendant group; FRET; Electrochemical measurements; Optical and Photovoltaic properties

\section{$\underline{\text { FULL TEXT }}$}


(C) 2016 The Authors. Published by ESG (www.electrochemsci.org). This article is an open access article distributed under the terms and conditions of the Creative Commons Attribution license (http://creativecommons.org/licenses/by/4.0/). 